\title{
對李瑞全教授〈中國文化中的人 論與醫學：儒家之醫學模式〉- 文的回應
}

方旭東

李瑞全教授的〈中國文化中的人論與醫學: 儒家之醫學模式〉 稱得上是一篇宏文, 該文站在中西比較的高度提出了在現行西方 醫學模式之外創建新的醫學模式的構想, 這個新的醫學模式主要 基於 “中醫所含的文化意義, 特別是儒家對人之為人的價值, 以 及人與天地萬物的關係所提出的醫學理念” (李瑞全, 2015, 51)。 筆者一直從事儒學研究, 近年來又關注生命倫理學, 此文對筆者 的吸引力可想而知。

細繹李文, 李教授所理解的醫學模式, 主要是關於疾病的定 義以及治療的原理。正是在這個意義上, 他認為, 中醫提出了不 同於西方的醫學模式, 因為中醫所理解的疾病 “基本上是陰陽氣 化之失調”, 其診斷與治療 “參照陰陽五行的理論來進行”。(李 瑞全，2015，62）這與西方醫學模式（尤其是傳統醫學模式）迥 然不同, 因為, 在後者那裡, “疾病的問題和醫療純是物質的身 體”, “疾病的最後原因即在物理的層面來驗證”。(李瑞全, $2015,50)$

方旭東, 華東師範大學哲學系教授, 中國上海, 郵編：200241。

《中外醫學哲學》XIII:2 (2015 年) : 頁 71-74。

(C) Copyright 2015 by Global Scholarly Publications. 
筆者對西方醫學素無研究, 對李教授有關西方醫學模式的理 解無從判斷, 故不予置評。在此, 筆者主要想就李教授提出的儒 家醫學模式做一點討論，算是對李文的一種呼應。

雖然李文主要是為儒家醫學模式張目，但令筆者感到美中不 足的是, 真正能夠説明儒家醫學模式的內容還嫌太少。李教授首 先花了大量篇幅敘述中醫理論。但眾所周知, 中醫並非儒學一家 可以範圍。中醫對疾病的診斷與治療主要參照陰陽五行的理論來 進行, 而陰陽五行之説來源複雜, 並非純正的儒學, 至少不是儒 家最有代表性的理論。就此而言, 固然可以説中醫提出了一種不 同於西方的醫學模式, 存在著一種中醫醫學模式, 卻不能説, 這 種模式就是儒家的。要證成儒家之醫學模式, 顯然還需要更多説 明。李教授在後面亦強調, 在中醫的學理中, 能使醫病感通, 使 身心與宇宙氣化合一和相應的是儒家的“仁” 與 “仁心” 的觀 念。（李瑞全，2015，58）然而，“醫乃仁術” 的觀念更多是指 醫者應具備 “心存仁義” 之德, 是對醫德的要求。在此意義上, 它還不足以構成與西方相區別的一種醫學模式。因為, 不難想見, 西醫同樣也有對救死扶傷、無私奉獻這樣的醫德的要求。

不過，李教授強調生命感通對於儒家醫學模式的意義，這是 富於啟發性的觀點。只是, 以筆者之見, 對醫學模式具有意義的 生命感通主要不是體現在李教授所説的這種 “醫病感通”上，而 在於：它提出了西方醫學模式當中所沒有涉及的由於生命不能感 通而產生的價值主體失落的精神疾病。李教授在談到“心靈疾病 的治療” 時對此有所述及（李瑞全，2015，64），但似乎還沒有 十分自覺, 因為他在後面談到由生命不能感通帶來的疾病時, 又 將精神病、“平常的一些違背倫常或合理的規範的表現”描述為 其嚴重形式。(李瑞全，2015，64)

精神疾病，西醫亦有對治之法，談不上是儒家醫學模式（如 果有的話）的特色。至於 “平常的一些違背倫常或合理的規範的 表現”, 有些可以歸為精神疾患, 有些則屬於文化價值或社會習 
俗之間的衝突, 並不真的就是疾病。真正能夠反映儒家醫學模式 對疾病獨特理解的, 是那種由於心靈不能感通, 失去作為價值、 行動主體的能力而產生的疾病, 其表徵是不能自作主章, 不能與 他人相通, 不能與最高的天道相通。這類情況在西方醫學當中, 甚至在傳統中醫當中, 都不被理解為疾病, 更不會施以治療。但 從人的心靈的暢達、繁㮡(flourishing)來看, 它的確是一種心靈的 㽽疾, 儒學尤其對它給予關注, 而治療的手段則是訴諸所謂心性 修養的工夫論, 從而也有別於訴諸信仰、超越力量的那些宗教傳 統。這樣的例子在儒學中俯拾皆是, 以前學界似乎還沒有從醫學 模式角度給予注意。以下，筆者試舉一例略為説明。

曾經有位學人向朱子(1120-1200)連篇累牘地訴説舉業失利 給自己帶來的痛苦, 朱子的回信僭然就跟醫生給病人看病一樣, 先分析病因： “必是當時於此見得太重, 所以如此執著, 放舍不 下”，接著開出藥方，甚至連每天服 “藥” 的次數與 “劑量” 都 做了詳細説明：“但請逐日那三五分功夫, 將古今聖賢之言剖析 義利處反復熟讀, 時時思省義理何自而來, 利欲何從而有, 二者 於人孰親孰疏、孰輕就重, 必不得已, 孰取就舍、孰緩孰急。將 古今聖賢之言剖析義利處反復熟讀”。考慮到對方可能將信將 疑, 朱子又特別喝咐, 這個方子是慢慢見效: “初看時似無滋味, 久之須自見得合剖判處, 則自然放得下矣”。( 朱喜, 2002, 2568-2569)

説朱子對待上述為科舉失利所困擾的學者像醫生對待病 人, 並非誇張。事實上, 朱子在分析學者從事科舉之弊時, 直接 用了 “病” 這樣的詞語來對事狀進行描述：“大抵今日後生輩以 科舉為急, 不服聽人説好話, 此是大病。須先與説破此病, 令其 安心俟命, 然後可教” (朱喜, 2002，2278-2279），“大抵今之 學者之病, 最是先學作文干祿, 使心不寧靜, 不暇深究義理, 故 於古今之學、義利之間, 不復能察其界限分別之際, 而無以知其 輕重取捨之所宜。” ( 朱喜, 2002，2777) 
朱子所關注的, 是學者內心的寧靜, 是精神的完滿充實。世 俗中人汲汲於名利, 在一般的醫者看來, 只要沒有頭疼腦熱, 就 不是病, 而在朱子看來, 這其實是對人身心極有妨害的 “大病”。 那麼, 這種心靈疾病又如何醫治呢? 朱子推薦的醫方是, 要熟讀 聖賢之書（讀書），樹立崇高的人生理想（立志），要在義利之 間分清輕重取捨（明理）。簡而言之, 是要修身, 要在身心上做 工夫。這個部分, 正是理學富有特色的工夫論。（方旭東, 2009 , 374-393)

限於篇幅, 不能詳論。無論如何, 今天我們要構建一個不同 於西方的中國醫學模式, 儒學 (尤其是理學) 的工夫論是值得好 好發掘的重要思想資源。

\section{參考文獻}

方旭東：〈應舉與修身——道學的身心治療之術〉, 載吳震編, 《宋代 新儒學的精神世界—以朱子學為中心》, 上海: 華東師範大學 出版社, 2009 • FANG Xudong. "Taking Part in Imperial Examination and Self Cultivation: Neo-Confucian Physical and Mental Therapy," in The Spiritual World of Neo-Confucian in Song Dynasty: Centralized on the Learning of ZHU Zi, edited by WU Zhen (Shanghai: East China Normal University Press, 2009).

朱 喜: 《朱子全書》, 第 22,23 冊, 上海: 古籍出版社、安徽: 安徽 教育出版社, $2002 \circ \mathrm{ZHU}$ Xi. The Complete Works of ZHU Zi, Vol. 22 \& 23 (Shanghai: Ancient Books Publishing House, Anhui: Anhui Education Press, 2002).

李瑞全: 〈中國文化中的人論與醫學: 儒家之醫學模式〉, 載范瑞平編, 《中外醫學哲學》, 2015 年, 第 13 卷, 第 2 期, 頁 49-66 LEE Shui Chuen. "Humanity and Medicine in Chinese Culture: A Confucian Medical Model," International Journal of Chinese \& Comparative Philosophy of Medicine, edited by FAN Ruiping, 13:2(2015), pp.49-66. 